\title{
Renal Hemodynamic Response to Atrial Natriuretic Factor in Fetal and Newborn Sheep
}

\author{
VENANCE A. VARILLE, KENNETH T. NAKAMURA, OLIVA J. MCWEENY, \\ G. PAUL MATHERNE, FRANCINE G. SMITH, AND JEAN E. ROBILLARD \\ Department of Pediatrics and the Cardiovascular Research Center, University of Iowa College of Medicine, Iowa \\ City, Iowa 52242
}

\begin{abstract}
We have previously demonstrated that systemic atrial natriuretic factor (ANF) infusion induced a renal vasoconstrictor response in fetal and newborn sheep. The present study was designed to test the hypothesis that the fetal and neonatal renal vasculatures do, in fact, vasodilate in response to ANF but that this effect is negated by vasoconstrictor compensatory mechanisms when ANF is infused systemically. To test this hypothesis, the renal hemodynamic response to intrarenal infusion of ANF was studied in chronically instrumented fetal (125-135 d of gestation; term $145 \mathrm{~d})$ and newborn (8-15 d) sheep. Intrarenal infusion of ANF (0.125 to $4.0 \mu \mathrm{g} / \mathrm{kg}$ of body wt in fetuses and 0.25 to $8.0 \mu \mathrm{g} / \mathrm{kg}$ in newborns) had no significant effect on mean arterial blood pressure and heart rate. However, ANF produced a concentration-dependent increase in renal blood flow velocity $(F=40.9, p<0.001)$ and a decrease in renal vascular resistance $(F=38.3, p<$ 0.001 ) in both groups. The magnitude of changes in renal blood flow velocity and renal vascular resistance expressed as percentage of changes $(\% \Delta)$ from control values, were similar $(p>0.05)$ in both fetal and newborn sheep during intrarenal infusion of ANF. These results demonstrate that ANF exerts direct vasodilator action on the fetal and neonatal renal vasculature and that the renal vasoconstriction previously observed during systemic infusion of ANF was probably secondary to activation of compensatory mechanisms. (Pediatr Res 25:291-294, 1989
\end{abstract}

\section{Abbreviations}

ANF, atrial natriuretic factor

$\mathrm{RBF}$, renal blood flow

RBFV, renal blood flow velocity

RVR, renal vascular resistance

$\% \Delta$, percentage of change

$\mathrm{D} 5 \mathrm{~W}, 5 \%$ dextrose in water

It has been demonstrated that ANF can be synthesized, stored and secreted by the fetal mammalian heart $(1,2)$. Studies in sheep (3-5), rats (1), and humans (6) have shown that ANF is present in fetal blood during the last part of gestation.

Received August 23, 1988; accepted November 4, 1988.

Correspondence Jean E. Robillard. M.D., Department of Pediatrics, University of Iowa Hospitals and Clinics, Iowa City, IO 52242.

Supported in part by USPHS Grants DK-38302, HD-20576, HL-14388, and HL-35600. VAV is supported by the Coca-Cola Nutrition Research Foundation. GPM is supported by National Heart, Lung and Blood Institute Training Grant ST32-HL-07413. KTN was the recipient of Clinical Investigator Award HD-00670. FGS is supported by a C.J. Martin Fellowship from the National Health and Medical Research Council of Australia.
Recent studies by our group (3) as well as by others $(5,7)$ suggest that the cardiovascular, renal hemodynamic, and possibly renal function responses to continuous intravenous infusion of ANF change during maturation. It has been found that the natriuresis and chloruresis produced by systemic infusion of ANF is of greater magnitude in adult than in fetal sheep (3). Systemic ANF infusion decreases arterial blood pressure and increases heart rate in newborn and adult sheep (3). In fetal sheep, ANF produces either a decrease $(7)$ or no change $(3,5)$ in arterial blood pressure associated with either a rise $(5,7)$ or no change (3) in heart rate. It has also been demonstrated that systemic ANF infusion decreases RBF and increases RVR in fetal and newborn animals but decreases RVR in adult sheep (3).

No studies have demonstrated if this renal vasoconstrictor response to systemic ANF infusion is particular to the renal vasculature of developing animals or is secondary to compensatory mechanisms. The present study was designed to evaluate the renal hemodynamic response to direct intrarenal infusion of ANF in conscious and chronically instrumented fetal and newborn sheep and to test the hypothesis that ANF does relax the renal vasculature during renal maturation.

\section{MATERIALS AND METHODS}

Animal preparation and surgical procedures. Fetuses of eight pregnant sheep of Dorset and Suffolk mixed breeding (3.27 \pm $0.11 \mathrm{~kg}$ ) were studied at $125-135 \mathrm{~d}$ of gestation (term being 145 d). Gestational ages were based on the induced ovulation technique as previously described (8).

Ewes were fasted for $24 \mathrm{~h}$ before surgery. General anesthesia of the ewe and fetal surgery were performed as previously described (9). Briefly, the ewe was anesthetized with a mixture of $1 \%$ halothane, $33 \%$ oxygen and $66 \%$ nitrous oxide. The uterus was opened and polyethylene catheters (outer diameter, 1.27 $\mathrm{mm}$; inner diameter, $0.86 \mathrm{~mm}$ ) were inserted in both femoral veins and arteries. A catheter was also secured in the amniotic cavity for intrauterine pressure recording. The left kidney of the fetus was exposed through a left flank incision. A Doppler flow probe was secured around the renal artery with care being taken to not interfere with renal innervation. Thereafter, a nonobstructive renal artery catheter was implanted using the method described by Herd and Barger (10) and previously used by Nakamura et al. (11). The Doppler flow probe and the renal artery catheter were secured to the renal capsule.

After suturing all fetal incisions, the fetal membranes, the uterine cavity and the maternal abdominal wall were closed in separate layers. At the end of surgery, ampicillin (1 g) was administered intramuscularly to the ewe and infused into the amniotic cavity. All catheters were impregnated before surgery with dimethyl polysiloxane (Acumetric, Elizabethtown, CT) to reduce clotting.

After surgery, the ewe was kept in a restricted area and fed a 
standard diet. The animal was usually standing and eating within $1 \mathrm{~h}$ after surgery. Before the start of each experiment, fetal wt was estimated according to the following formula: fetal body wt $(\mathrm{kg})=(0.096 \times$ gestational age $(\mathrm{d})-9.233,(r=0.85, p<0.001)$ (9).

Seven newborn lambs $(7.6 \pm 0.5 \mathrm{~kg})$ between the ages of 8 and $15 \mathrm{~d}$ were also studied. Surgery in the newborn lambs was similar to that described for the fetuses. However, an additional catheter was placed in the left ventricle through the femoral artery (with catheter position documented by pressure tracing) for infusion of radioactive microspheres to quantitate $\mathrm{RBF}$ in $\mathrm{mL} / \mathrm{min}$. After surgery, newborn lambs were returned to their mothers.

Procedures on the use of sheep in this project were approved by the University of Iowa's Animal Care and Use Committee, and are in accordance with PHS policies and the Guide for the Care and Use of Laboratory Animals (NIH Publication No. 8523, revised 1985).

Physiologic studies. Before each study, newborn and fetal sheep were allowed 3 and $6 \mathrm{~d}$, respectively, to recover from surgery. At the time of the study, the pregnant ewe was transferred to a small cart, permitting it to stand. Each lamb was supported upright in a harness.

A 60 -min equilibration period was allowed to permit the animal to adapt to the laboratory environment and to ensure stability of the preparation before starting the experiment. Arterial blood was collected from the femoral artery catheter at the beginning and end of each experiment to determine arterial $\mathrm{pH}$ and blood gases $\left(\mathrm{P}_{\mathrm{CO}_{2}}, \mathrm{P}_{\mathrm{O}_{2}}\right)$. During the study, pregnant ewes were allowed free access to water, and newborn lambs received an intravenous infusion of $\mathrm{D} 5 \mathrm{~W}$ and $0.2 \%$ sodium chloride given at a rate of $100 \mathrm{~mL} \cdot \mathrm{kg}$ body $\mathrm{wt}^{-1} \cdot 24 \mathrm{~h}^{-1}$. Furthermore, D5W was infused continuously at a rate of $0.1 \mathrm{~mL} / \mathrm{min}$ into the renal artery of fetal sheep and newborn lambs.

Synthetic $\alpha$-human atriopeptin (ANF) (Peninsula Laboratories, Belmont, $\mathrm{CA}$ ) was diluted in D5W and infused directly into the renal artery in 2-fold increments ranging from 0.125 to $4 \mu \mathrm{g} /$ $\mathrm{kg}$ of body wt in fetuses and 0.25 to $8 \mu \mathrm{g} / \mathrm{kg}$ in newborn lambs. Each dose was infused directly into the renal artery as a $0.3-\mathrm{mL}$ infusion over $30 \mathrm{~s}$ using a Harvard pump. In addition, D5W was infused as a vehicle control. Doses of ANF and D5W were administered in a random sequence; each dose was given twice, and the two observations were averaged for further analysis. There was an interval of at least $5 \mathrm{~min}$ between each dose to allow RBFV, as determined by the Doppler flowmeter, to return to baseline. Usually RBFV was back to baseline $3 \mathrm{~min}$ after ANF administration.

During each experiment, arterial and amniotic pressures were recorded continuously using Statham P23Db pressure transducers (Statham Instruments, Schiller Park, IL). Fetal arterial pressure was corrected relative to concomitant amniotic pressure. Heart rate in fetal and newborn sheep was monitored with a cardiotachometer triggered from the arterial pressure pulse wave.

Changes in RBFV to the left kidney were monitored continuously using an ultrasonic pulsed Doppler flowmeter, modified from the original design of Hartley and Cole (12), and constructed by the University of Iowa Bioengineering Resource Facility (13). The validity of the pulsed Doppler flowmeter for use in determining $\% \Delta$ in RBFV in the present experimental model has previously been demonstrated (11). All hemodynamic data were continuously recorded on a Beckman R-611 recorder (Beckman Instruments, Inc., Palo Alto, CA) and simultaneously with an online computer (IBM-XT, IBM Instruments, Inc., Danbury, CT) using LABTECH NOTEBOOK (Laboratory Technologies Corporation, Wilmington, MA) and Lotus 1-2-3 (Lotus Development Corporation, Cambridge, MA) softwares. The correlation between manually derived and computer analyzed $\% \Delta$ in RBFV in 131 cases ranging from $-100 \%$ to $+107 \%$ was described by the equation: $\% \Delta$ in RBF calculated manually from graph paper $=3.6+(\% \Delta$ in RBF derived by computer calculation $\times 1.03) ; r=0.96, p<0.0001$.

To determine estimated ANF concentration in renal blood, baseline $\mathrm{RBF}$ in $\mathrm{mL} / \mathrm{min}$ was measured using the microsphere technique. Approximately $4.0 \times 10^{6}$ radioactive microspheres (15 $\pm 3 \mu \mathrm{m}$ diameter) labeled with either ${ }^{141} \mathrm{Ce},{ }^{46} \mathrm{Sc},{ }^{85} \mathrm{Sr}$, or ${ }^{95} \mathrm{Nb}$ (3M Co., St. Paul, MN) were infused over a 30 -s period into the fetal femoral vein catheter and then immediately flushed with $3 \mathrm{~mL}$ of $0.9 \%$ saline solution $(14,15)$. In newborn lambs, radioactive microspheres were infused into the left ventricular catheter. Blood for a lower body independent reference sample was collected from the femoral artery during a period of $3 \mathrm{~min}$ beginning $20 \mathrm{~s}$ before the injection of microsphere at a withdrawal rate of $1.94 \mathrm{~mL} / \mathrm{min}$ using a Harvard infusion-withdrawal pump. At the end of the experiment, the animals were killed with a lethal dose of pentobarbital sodium (Somlethal, MidTech., Inc., Elwood, KS). Animals were weighed, and the kidneys were removed for radioactivity determination.

To compare dose responses between fetal sheep and newborn lambs, estimated concentrations of ANF in renal blood were determined as previously described (11). The molar amount of ANF given was calculated by multiplying the ANF dose in $\mu \mathrm{g} /$ $\mathrm{kg}$ by the $\mathrm{wt}$ of the animals and dividing by ANF mol wt (3080.95). This value was then divided by $\mathrm{RBF}(\mathrm{mL} / \mathrm{min})$ to provide an approximation of molar concentration of ANF in renal blood.

\section{ANALYTICAL PROCEDURES}

Arterial blood for $\mathrm{pH} \mathrm{P}_{\mathrm{CO}_{2}}$, and $\mathrm{P}_{\mathrm{O}_{2}}$ was collected anaerobically in heparinized syringes, and measurements were immediately determined with the appropriate $\mathrm{pH}, \mathrm{P}_{\mathrm{CO}_{2}}$ and $\mathrm{P}_{\mathrm{O}_{2}}$ electrodes at $39^{\circ} \mathrm{C}$ using an IL-1303 pH/blood gas analyzer (Instrument Laboratory System, Houston, TX).

$\gamma$ emissions generated from the microspheres were measured in the left kidney and reference femoral arterial blood samples using a Beckman $300 \gamma$ spectrometer. Energy window ranges were set between $74-102 \mathrm{keV}$ for ${ }^{141} \mathrm{Ce}, 210-275 \mathrm{keV}$ for ${ }^{85} \mathrm{Sr}$, $310-410 \mathrm{keV}$ for ${ }^{95} \mathrm{Nb}$, and $420-580 \mathrm{keV}$ for ${ }^{46} \mathrm{Sc}$. Handling of the kidney before counting and isotope separation were as previously described $(14,15)$.

Computations and data analysis. $\mathrm{RBF}$, using the microsphere technique, was determined according to the following formula: $\mathrm{RBF}(\mathrm{mL} / \mathrm{min})=$ total kidney counts $\times$ reference flow from the femoral artery $(\mathrm{mL} / \mathrm{min}) /$ total femoral blood counts.

$\% \Delta \mathrm{RBFV}$ and $\% \Delta \mathrm{RVR}$ by use of the Doppler flow probe were calculated using the following formulas:

$$
\begin{aligned}
\% \Delta \mathrm{RBFV} & =\left[\left(\mathrm{E}_{\mathrm{ds}}-\mathrm{B}_{\mathrm{ds}}\right) / \mathrm{B}_{\mathrm{ds}}\right] \times 100 \\
\mathrm{RVR} & =\mathrm{PP} / \mathrm{DS} \\
\% \Delta \mathrm{RVR} & =\left[\left(\mathrm{RVR}_{\mathrm{e}}-\mathrm{RVR}_{\mathrm{b}}\right) / \mathrm{RVR}_{\mathrm{b}}\right] \times 100
\end{aligned}
$$

where $E_{d s}$ is the maximum Doppler shift in $\mathrm{kHz}$ during intrarenal ANF infusion and $B_{d s}$ is the baseline Doppler shift in $\mathrm{kHz}$; RVR is the renal vascular resistance expressed arbitrarily in $\mathrm{mm} \mathrm{Hg}$ / $\mathrm{kHz}$; $\mathrm{PP}$ is the renal perfusion pressure estimated to be equal to the mean aortic pressure (mm Hg); DS is the Doppler shift $(\mathrm{kHz})$; and $R_{V R}$ and $R_{V} R_{b}$ are the RVR during the experimental and baseline periods, respectively.

Comparisons of dose-response curves between fetal and newborn sheep were performed by 2-way ANOVA for repeated measures with Duncan's multiple range test (16). Comparisons between control and each concentration of ANF for each age group were made by use of randomized block ANOVA and Dunnett's multiple comparison procedure. Paired $t$ tests were used to compare baseline arterial blood values at the beginning and at the end of the experiment. Unpaired $t$ tests were used to compare baseline values between fetal and newborn sheep. The term "significant" is used throughout to describe changes with a total $p$ value of $<0.05$ in a 2 -sided significance limit. Values are expressed as means \pm SEM.

\section{RESULTS}

Baseline arterial $\mathrm{pH}, \mathrm{P}_{\mathrm{CO}_{2}}$ and $\mathrm{P}_{\mathrm{O}_{2}}$ and hematocrit values are presented in Table 1 . No changes were observed in these values 
after intrarenal infusion of ANF. Baseline RBF values measured by the microsphere technique and expressed in $\mathrm{mL} / \mathrm{min}$ or corrected for kidney wt were lower in fetuses than in newborn lambs $(p<0.05$ ) (Table 1). RVR expressed in $\mathrm{mm} \mathrm{Hg} / \mathrm{ml} / \mathrm{min}$ of renal blood flow was significantly higher in fetal sheep than in newborn lambs $(p<0.05)$ (Table 1).

Effect of intrarenal ANF infusion on arterial blood pressure, heart rate, and renal hemodynamics. Intrarenal infusion of ANF had no significant effect on mean arterial blood pressure and heart rate values in fetal and newborn sheep (Fig. 1).

Intrarenal infusion of ANF produced dose-dependent increases in mean RBFV in fetal and newborn sheep $(\mathrm{F}=40.9, p<0.001)$ (Fig. 2). Each dose of ANF produced a renal vasodilation that was significantly greater than during infusion of D5W (control).

Table 1. Baseline values in fetal and newborn sheep*

\begin{tabular}{|c|c|c|}
\hline & $\begin{array}{l}\text { Fetus } \\
(n=8)\end{array}$ & $\begin{array}{l}\text { Newborn } \\
(n=7)\end{array}$ \\
\hline $\mathrm{pH}$ & $7.37 \pm 0.01$ & $7.42 \pm 0.06 \dagger$ \\
\hline $\mathrm{P}_{\mathrm{CO} 2}(\mathrm{~mm} \mathrm{Hg})$ & $51 \pm 1$ & $42 \pm 2 \dagger$ \\
\hline $\mathrm{P}_{\mathrm{O} 2}(\mathrm{~mm} \mathrm{Hg})$ & $21 \pm 1$ & $86 \pm 4 \dagger$ \\
\hline Hematocrit (\%) & $40 \pm 2$ & $32 \pm 2 \dagger$ \\
\hline \multicolumn{3}{|l|}{ RBF to left kidney } \\
\hline $\mathrm{mL} / \mathrm{min}$ & $25 \pm 3$ & $90 \pm 6 \dagger$ \\
\hline $\mathrm{mL} \cdot \mathrm{min}^{-1} \cdot \mathrm{g}$ kidney $\mathrm{wt}^{-1}$ & $1.87 \pm 0.87$ & $5.79 \pm 1.58 \dagger$ \\
\hline $\begin{array}{l}\text { RVR to left kidney }(\mathrm{mm} \mathrm{Hg} \text {. } \\
\left.\qquad \mathrm{ml}^{-1} \cdot \mathrm{min}^{-1}\right)\end{array}$ & $1.85 \pm 0.12$ & $0.82 \pm 0.05 \dagger$ \\
\hline $\begin{array}{l}\text { Mean arterial blood pressure } \\
\quad(\mathrm{mm} \mathrm{Hg})\end{array}$ & $47 \pm 3$ & $72 \pm 2 \dagger$ \\
\hline Heart rate (beats/min) & $161 \pm 6$ & $215 \pm 13 \dagger$ \\
\hline
\end{tabular}

$*$ Values are means \pm SEM.

$\dagger p<0.05$ when newborn values are compared with fetal values.
Heart Rate

(beats/min)

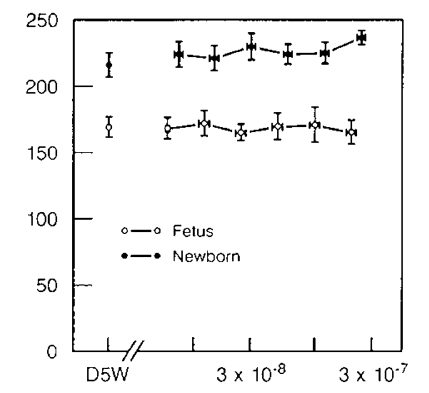

Mean Arterial Blood

Pressure $(\mathrm{mmHg})$

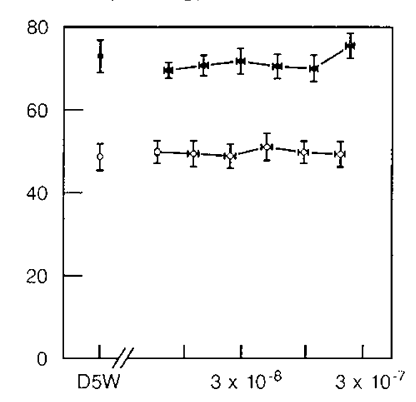

Renal ANF Concentration (M)

Fig. 1. Mean arterial blood pressure and heart rate before and during intrarenal ANF infusion. (Values are means \pm SEM. Fetus, $n=8$; newborn, $n=7$.)
$\%$ Increase
in RBFV

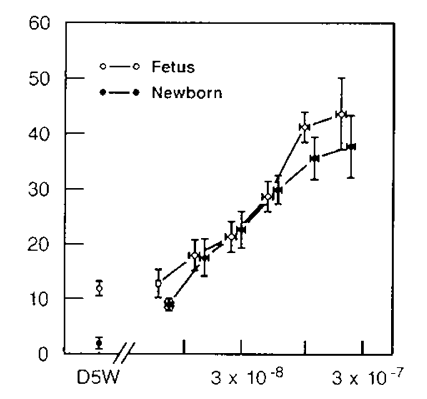

$\%$ Decrease in RVR

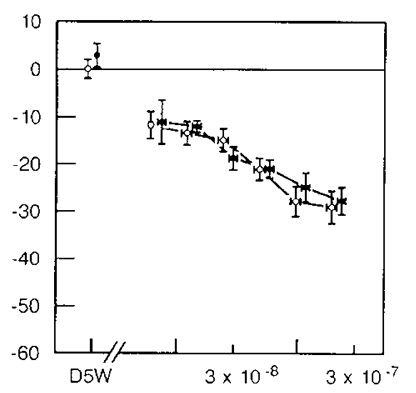

Renal ANF Concentration (M)

Fig. 2. Effect of intrarenal ANF infusion on $\% \Delta$ in RBFV and RVR. (Values are means \pm SEM. Fetus, $n=8$; newborn, $n=7$.)
The renal vasodilatory effect of ANF was similar in both fetal and newborn sheep $(F=0.58, p=0.45)$, and no difference at any concentration was observed between both groups of animals.

Parallel to the changes in RBFV, intrarenal ANF infusion decreased RVR in a dose-dependent fashion $(\mathrm{F}=38.3, p<$ 0.001 ) (Fig. 2). The decrease in RVR was similar in both fetal and newborn sheep $(\mathrm{F}=1.00, p=0.33)$.

\section{DISCUSSION}

The present study demonstrates that intrarenal infusion of ANF produces renal vasodilation and decreases renal vascular resistance in a dose-dependent fashion in fetal and newborn sheep. These results differ from a previous study (3) in fetal and newborn sheep where it was shown that systemic intravenous infusion of ANF was associated with a decrease in RBFV and a rise in RVR.

Differences between these two studies are intriguing. However, the present results suggest that ANF does not exert a direct vasoconstrictor action on the fetal and neonatal renal vasculature and that the site of administration of the peptide as well as the duration of the infusion play an important role in the renal hemodynamic response to ANF, as previously suggested in adults (17); systemic infusion of the peptide produces a renal vasoconstriction (3), whereas intrarenal bolus infusion produces renal vasodilation. One may speculate that systemic infusion of ANF increases sympathetic tone, which opposes the renal vasodilatory action of ANF $(18,19)$, whereas ANF infused intrarenally is cleared rapidly by the kidney (20) and has little or no effect on sympathetic vasoconstrictor tone. In support of this hypothesis Lappe et al. (18) have demonstrated that surgical denervation or chemical sympathectomy abolishes the renal vasoconstrictor response associated with systemic ANF infusion in spontaneously hypertensive rats. Furthermore, it has been demonstrated that norepinephrine can also inhibit the vasodilatory influence of ANF (21). Other factors, such as a decrease in cardiac output $(22,23)$, activation of the renin-angiotensin system (24), and redistribution of blood flow away from the renal circulation (25) may have also contributed to the decrease in total renal blood flow observed during systemic infusion of ANF in previous studies (3).

Finally, as the estimated concentration of ANF in renal blood $\left(5.75 \pm 0.65 \times 10^{-9} \mathrm{M}\right.$ to $\left.2.19 \pm 0.17 \times 10^{-7} \mathrm{M}\right)$ that produces renal vasodilation during intrarenal infusion of ANF is higher than the highest plasma ANF concentration $\left(0.5 \times 10^{-9} \mathrm{M}\right)$ achieved during systemic ANF infusion (3), one may suggest that ANF has no direct renal vasoconstrictor effect. It is also shown that the lowest estimated renal blood concentration of ANF $(5.75$ $\pm 0.65 \times 10^{-9} \mathrm{M}$ ) producing renal vasodilation in the present in vivo study is close to the in vitro ANF concentration $\left(1.1 \times 10^{-9}\right.$ M) needed for threshold stimulation of cGMP in vascular smooth muscle (26).

The present study also demonstrates that the magnitude of the renal vasodilatory response to intrarenal infusion of ANF (expressed as $\% \Delta$ from baseline) is similar in fetal and newborn sheep. In that regard, these results differ from previous studies (27-29) demonstrating that the renal vasodilatory response to $\beta$ adrenoceptor stimulation is greater in fetal sheep than in newborn lambs. A recent study (30) using forskolin, a drug known to activate adenylate cyclase directly (31), has suggested that the greater $\beta$-adrenoceptor-mediated renal vasodilation in fetal sheep may be at the receptor-hormone level. Thus, the present results suggest that the cGMP-dependent renal vasodilatory mechanism (stimulated by ANF) is already mature by the end of gestation, whereas the ability of the renal vasculature to respond to $\beta$ adrenoceptor stimulation, a cAMP-dependent mechanism, is higher in fetuses than postnatally (30).

In summary, the present study demonstrates that ANF exerts direct vasodilator action on the fetal and neonatal renal vasculature and suggests that the decrease in renal blood flow previously observed during systemic infusion of ANF (3) was probably 
secondary to changes in systemic hemodynamics $(22,25)$ and activation of compensatory mechanisms $(18,19)$. Finally, it is shown that the renal vasodilatory response to intrarenal ANF infusion is similar in fetal and newborn sheep. The role of ANF in controlling renal hemodynamics and function during the transition from fetal to newborn life remains to be investigated.

\section{REFERENCES}

1. Wei YF, Rodi CP, Day ML, Wiegand RC, Needleman LD, Cole BR, Needleman P 1987 Developmental changes in the rat atriopeptin hormonal system. J Clin Invest 79:1325-1329

2. Toshimori H, Toshimori K, Oura C, Matsuo H 1987 Immunohistochemical study of atrial natriuretic polypeptides in the embryonic, fetal and neonatal rat heart. Cell Tissue Res 248:627-633

3. Robillard JE, Nakamura KT, Varille VA, Andresen AA, Matherne GP, Van Orden DE 1988 Ontogeny of the renal response to natriuretic peptide in sheep. Am J Physiol 254:F634-F641

4. Cheung CY, Gibbs DM, Brace RA 1987 Atrial natriuretic factor in maternal and fetal sheep. Am J Physiol 252:E279-E282

5. Ervin MG, Ross MG, Castro R, Sherman D, Lam RW, Castro L, Leake RD, Fisher DA 1988 Ovine fetal and adult atrial natriuretic factor metabolism. Am J Physiol 254:R40-R46

6. Robillard JE, Weiner CP 1988 Atrial natriuretic factor in the human fetus: effect of volume expansion. J Pediatr 113:552-555

7. Brace RA, Cheung CY 1987 Cardiovascular and fluid responses to atrial natriuretic factor in sheep fetus. Am J Physiol 253:R561-R567

8. Jennings JJ, Crowley JP 1972 The influence of mating management on fertility in ewes following progesterone-PMS treatment. Vet Rec 90:496-498

9. Robillard JE, Weitzman RE 1980 Developmental aspects of the fetal renal response to exogenous arginine vasopressin. Am J Physiol 238:F407-F414

10. Herd JA, Barger AC 1964 A simplified technique for chronic catheterization of blood vessels. J Appl Physiol 19:791-792

11. Nakamura KT, Felder RA, Jose PA, Robillard JE 1987 Effects of dopamine in the renal vascular bed of fetal, newborn and adult sheep. Am J Physiol 252:R490-R497

12. Hartley CJ, Cole JS 1974 An ultrasonic pulsed Doppler system for measuring blood flow in small vessels. J Appl Physiol 37:626-629

13. Haywood JR, Shaffer RA, Fastenow C, Fink GD, Brody MJ 1981 Regional blood flow measurement with pulsed Doppler flowmeter in conscious rat. Am J Physiol 241:H273-H278

14. Heymann MA, Payne BD, Hoffman JIE, Rudolph AM 1977 Blood flow measurements with radionuclide-labeled particles. Prog Cardiovasc Dis 20:55-79

15. Robillard JE, Weitzman RE, Burmeister L, Smith FG, Jr. 1981 Developmental aspects of the renal response to hypoxemia in the lamb fetus. Circ Res 48:128-138

16. Winer BJ 1971 Statistical Principles in Experimental Design (2nd edition) McGraw-Hill, New York, pp 559-571

17. Lappe RW, Todt JA, Wendt RL 1986 Hemodynamic effects of infusion versus bolus administration of atrial natriuretic factor. Hypertension 8:866-873

18. Lappe RW, Todt JA, Wendt RL 1985 Mechanism of action of vasoconstrictor responses to atriopeptin II in conscious SHR. Am J Physiol 249:R781-R786

19. Sasaki A, Kida O, Kangawa K, Matsuo H, Tanaka K 1986 Involvement of sympathetic nerves in cardiosuppressive effects of alpha-human atrial natriuretic polypeptide (alpha-hANP) in anesthetized rats. Eur $J$ Pharmacol 120:345-349

20. Weselcouch EO, Humphrey WR, Aiken JW 1985 Effect of pulmonary and renal circulations on activity of atrial natriuretic factor. Am $J$ Physiol 249:R595-R602

21. Kuchel O, Debinski W, Racz K, Buu NT, Garcia R, Cusson JR, Larochelle P, Cantin M, Genest J 1987 An emerging relationship between the sympathetic nervous system and ANF. Life Sci 40:1545-1551

22. Breuhaus BA, Saneii HH, Brandt MA, Chimoskey JE 1985 Atriopeptin II lowers cardiac output in conscious sheep. Am J Physiol 249:R776-R780

23. Parkes DG, Coghlan JP, McDougall JG, Scoggins BA 1987 Hemodynamic effects of atrial natriuretic peptide in conscious sheep. Clin Exp Hypertens A9:2143-2156

24. Showalter CJ, Zimmerman RS, Schwab TR, Edwards BS, Opgenorth TJ, Burnett JC 1988 Renal response to atrial natriuretic factor is modulated by intrarenal angiotensin II. Am J Physiol 254:R453-R456

25. Chien YW, Frohlich ED, Trippodo NC 1987 Atrial natriuretic peptide increases resistance to venous return in rats. Am J Physiol 252:H894-H899

26. Sato M, Abe K, Takeuchi K, Yasujima M, Omata K, Hiwatari M, Kasai Y, Tanno M, Kohzuki M, Kudo K, Yoshinaga K, Inagami T 1986 Atrial natriuretic factor and cyclic guanosine $3^{\prime}, 5^{\prime}$-monophosphate in vascular smooth muscle. Hypertension 8:762-771

27. Robillard JE, Nakamura KT, Wilkin MK, McWeeney OJ, DiBona GF 1987 Ontogeny of renal hemodynamic response to renal nerve stimulation in sheep. Am J Physiol 252:F605-F612

28. Nakamura KT, Matherne GP, Jose PA, Alden BM, Robillard JE 1987 Ontogeny of renal $\beta$-adrenoceptor-mediated vasodilation in sheep: comparison between endogenous catecholamines. Pediatr Res 22:465-470

29. Nakamura KT, Matherne GP, Jose PA, Alden BM, Robillard JE 1988 Effects of epinephrine on the renal vascular bed of fetal, newborn, and adult sheep. Pediatr Res 23:181-186

30. Nakamura KT, Alden BM, Matherne GP, Jose PA, Robillard JE 1988 Ontogeny of renal hemodynamic response to terbutaline and forskolin in sheep. J Pharmacol Exp Ther 247:453-459

31. Daly JW 1984 Forskolin, adenylate cyclase, and cell physiology: an overview. In: Greengard P (ed) Advances in Cyclic Nucleotide and Protein Phosphorylation Research. Raven Press, New York, 17:81-89 